\title{
Eisenmenger Syndrome - a Case Report
}

\author{
MIA Khan ${ }^{1}, \mathrm{SY} \mathrm{Ali}^{2}$, MS Hoque ${ }^{3}$
}

\begin{abstract}
:
Eisenmenger syndrome (ES), the most advanced form of pulmonary arterial hypertension associated with congenital heart disease, is a devastating condition that has a considerable impact on patient's life. Patients who develop ES typically exhibit one or more of a range of cardiac defects including ventricular septal defects (VSD), atrial septal defects (ASD) and patent ductus arteriosus (PDA). The nature of the congenital defect underlying ES is important because it has prognostic implications. Early diagnosis \& treatment of cardiac defect before development of pulmonary hypertension is the key to definite management, otherwise only supportive management can be offered. Our patient Mr. Abdul Khaleque, 55 years old, businessman, non diabetic, non hypertensive admitted in DAMCH, cardiac unit with the complaints of shortness of breath on exertion since childhood, bluish discoloration of nails and toes for 10 years, headache and vertigo for 2 weeks. Initially it was during severe exertion and relieved by rest. Gradually the severity of breathlessness has increased. Now he has developed NYHA class III. He had history of repeated attacks of cough with expectoration of mucoid sputum with occasional scanty amount of blood which did not foul smell and did not change with posture. We diagnose him as Eisenmenger syndrome secondary to ASD and treat him with only medical measure.
\end{abstract}

Key words: Eisenmenger syndrome, atrial septal defect, ventricular septal defect, patent ductus arteriosus, congenital cardiac defect, septum primum, septum secendum.

\section{Introduction:}

Eisenmenger syndrome refers to any untreated congenital cardiac defect with intracardiac communication that leads pulmonary hypertension, reversal of flow and cyanosis ${ }^{1-3}$. The previous left to right shunt is converted into a right to left shunt secondary to elevated pulmonary artery pressure and associated pulmonary vascular disease. Lesions in ES such as large septal defect are characterized by high pulmonary pressure and/or a high pulmonary flow state. Development of the syndrome represents a point at which pulmonary hypertension is irreversible and is an indication that the cardiac lesion is likely in-operable. ES was initially described in 1897 when Victor Eisenmenger reported it on a pt with symptoms of dyspnea and cyanosis from infancy that subsequently developed heart failure and succumbed to massive

1. Dr. Md. Isahaque Ali Khan, MBBS, D-Card, Associate Professor, Department of Cardiology, Diabetic Association Medical College, Faridpur.

2. Prof. Dr. Sk Yunus Ali, MBBS, DTCD, MD(Cardiology), Professor $\&$ Head, Department of Cardiology, Diabetic Association Medical College, Faridpur.

3. Dr. Mohammad Saiful Hoque, MBBS, M Phil (Radiology \& Imaging), Assistant Professor, Diabetic Association Medical College, Faridpur.

\footnotetext{
Address of correspondence :

Dr. Md. Isahaque Ali Khan, Associate Professor, Department of Cardiology, Diabetic Association Medical College, Faridpur.

Phone No:+88-01717010468, Email: drisahaq@gmail.com
}

haemoptysis. This was the first description of a link between a large congenital cardiac defect and the development of pulmonary hypertension ${ }^{4}$.

ES can cause serious complication in pregnancy, maternal mortality ranges from $30 \%$ to $40 \%$ and may be attributed to syncope, thromembolism, hypovolemia, haemoptysis or preclampsia. Most of the death occurs either during delivery or within the first week. Pregnant women with ES should be hospitalized after 20th weeks of pregnancy.

ES is more common with large VSD or PDA than with $\mathrm{ASD}^{5}$. Patients with ES are at particular risk for abrupt changes in afterload that exacerbate right to left shunting such as vasodilation, anaesthesia and pregnancy. During the past 50 yrs, the prevalence of ES in the western world has reduced by an estimated $50 \%$, resulting from advances in surgery and pediatric cardiology.

ES is still seen in older patients and occasionally in younger patients. They can survive 30 yrs or more after the onset of the syndrome.

ASD in which pulmonary flow is increased $50 \%$ above systemic flow (Flow rate of 1.5:1) are often large 
enough to be clinically recognizable and should be closed surgically. Closure can also be accomplished at cardiac catheterization using implantable closure devices. Severe pulmonary hypertension and shunt reversal are both contraindication to surgery ${ }^{6}$.

\section{Case Report:}

Mr. Abdul Khaleque, 55 years old, businessman, non diabetic, non hypertensive, smoker hailing from Barhatta, Netrokona was admitted in DAMCH on 02.01.2013 with the complaints of headache and vertigo for 2 weeks which was not associated with vomiting and blurring of vision. He had fatigability with lack of concentration on daily activities for 4 years, bluish discoloration with swelling of the fingers and toes for 10 years and exertional shortness of breath since childhood. Initially it was during severe exertion and relieved by rest and later it became continuous. It was not associated with seasonal variation. He had history of repeated attack of cough with scanty amount of haemoptysis which did not foul smell and did not change with posture and there was no seasonal variation. He did not give any history of pain and swelling of the joints, calf muscle, syncopal attack, chest pain, prolonged fever except occasional palpitation. On examination his appearance is dusky red with suffused conjuctiva, non iceteric, central cyanosis and clubbing present, oedema absent, JVP not raised, pulse $92 / \mathrm{min}$, BP $120 / 70 \mathrm{~mm}$ of $\mathrm{Hg}$, RR $18 / \mathrm{min}$, and temperature $98^{\circ} \mathrm{F}$. There was no chest wall deformity, apex beat in left 5 th intercostal space, just lateral to the mid clavicular line and normal in character. Palpable $\mathrm{p}_{2}$, left parasternal heave, epigastric pulsation were present but no thrill. $\mathrm{S}_{1}$ normal, $\mathrm{P}_{2}$ loud with narrow fixed splitting, ejection systolic murmur (2/6) in pulmonary area, no other added sound. All other systems were normal.

Investigations were done as follows, besides cardiac catheterization with coronary angiogram could be done if facility were available.

\section{Fig. I: ECG shows RBBB}

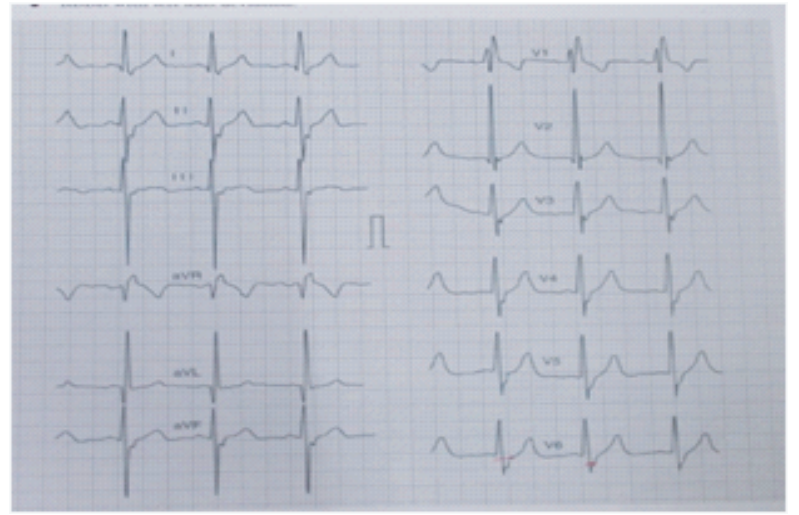

\begin{tabular}{ll}
\hline Investigation & Result \\
\hline $\mathrm{Hb}$ & $17 \mathrm{gm} / \mathrm{dl}$ \\
$\mathrm{ESR}$ & $03 \mathrm{~mm}$ in $1^{\text {st }}$ hour \\
WBC count & $9000 / \mathrm{cmm}$ \\
Neutrophil & $66 \%$ \\
Lymphocyte & $28 \%$ \\
Blood Film & Normal \\
S. Creatinine & $1 \mathrm{mg} / \mathrm{dl}$ \\
Liver function test & Normal \\
ECG & RBBB with RVH with \\
& left axis deviation \\
Chest X-Ray & Cardiomegaly, Fullness of \\
& pulmonary conus, Plethoric \\
& lung field, Dilated proximal \\
& pulmonary artery, Prunning \\
& of outer 1/3 of lung field \\
& IAS- Deficit, RV- Dilated, \\
& Mosaic flow seen and \\
bidirectionally, PASP- \\
Colour Doppler study
\end{tabular}

Fig. II: Chest $\mathrm{X}$-ray P/A view:

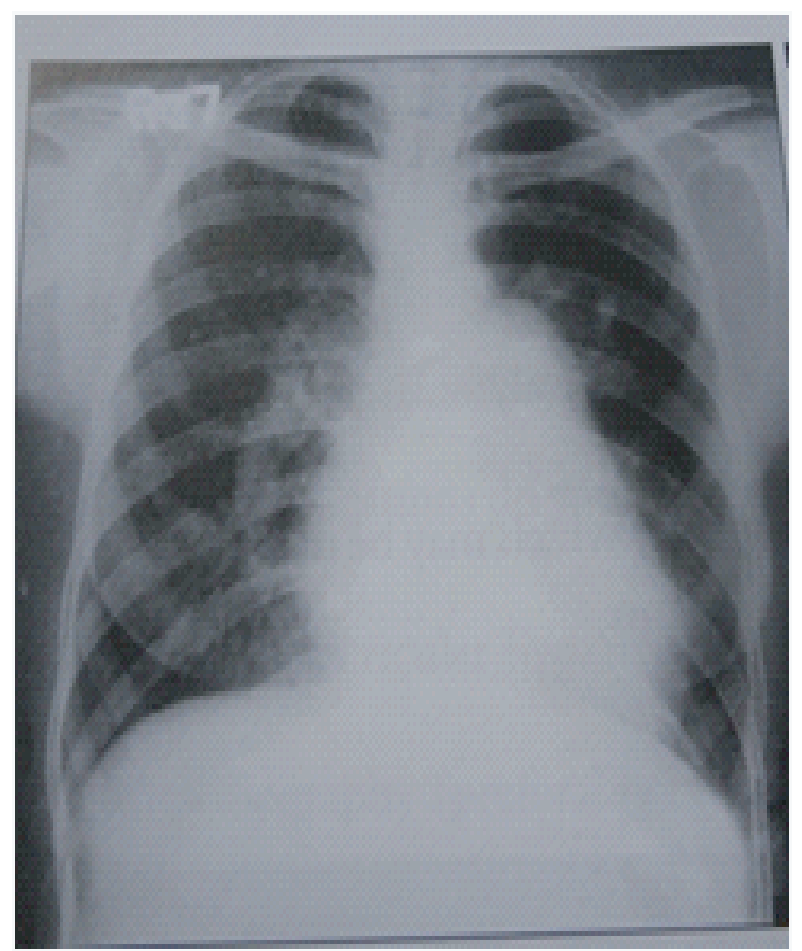




\section{Fig. III: Colour Doppler Echocardiography}
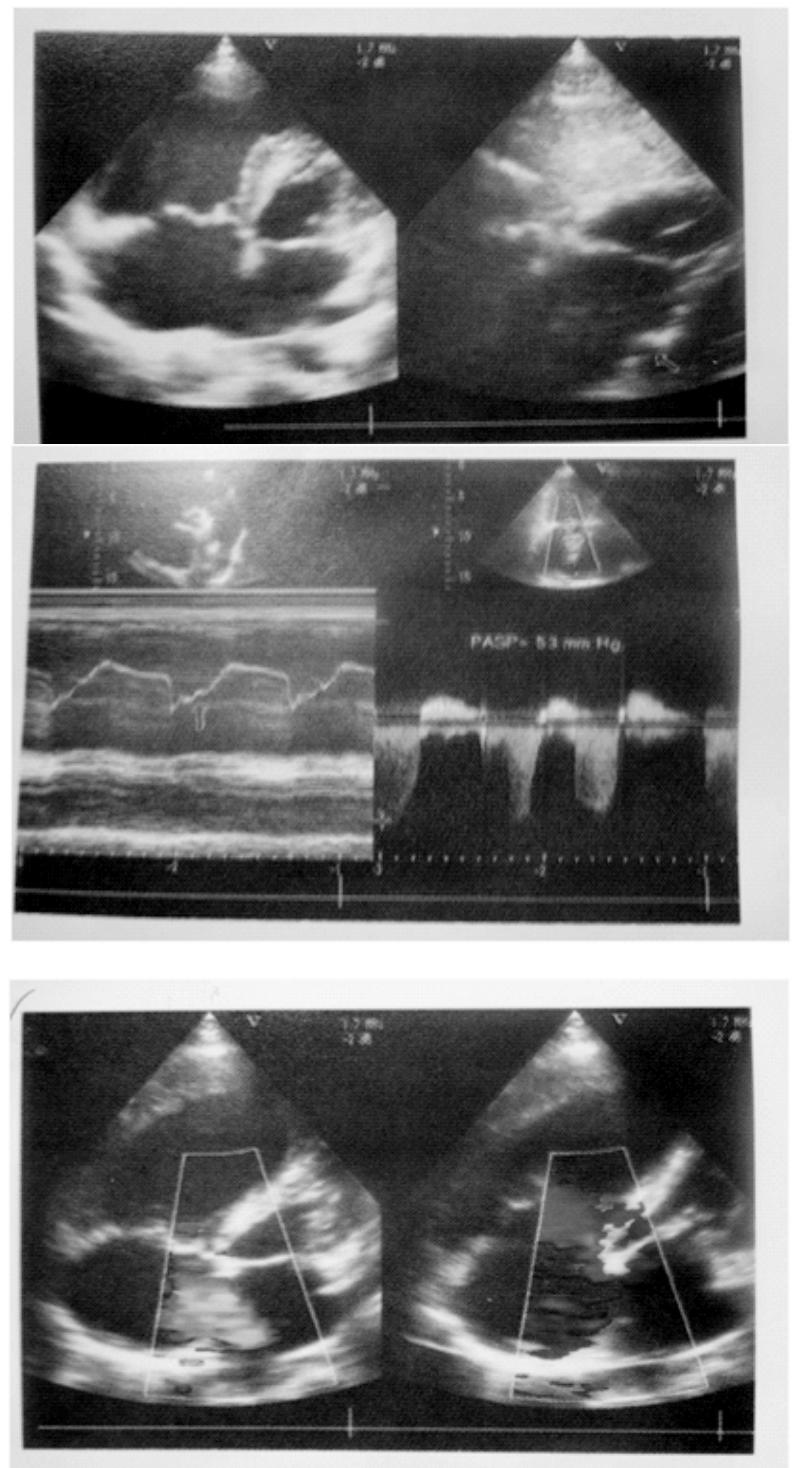

We diagnosed him as Eisenmenger syndrome secondary to ASD and treated by medical measures with significant improvement.

\section{Discussions:}

A number of congenital heart defects can cause ES including ASD, VSD, PDA and more complex types of acyanotic heart disease. ES is more common with VSD or PDA than with $\mathrm{ASD}^{2}$.

ES is still seen in older patients and occasionally in younger patients. ES patient survive 30 years or more after the onset of the syndrome. Early diagnosis and surgical treatment have a good prognostic value. If a patient is diagnosed at later stage, severe pulmonary hypertension and heart failure develop and the prognosis is $\mathrm{bad}^{7}$.
If the hole (ASD) in the heart is identified before it causes pulmonary hypertension. It can normally be repaired surgically thus can prevent the disease. After development of pulmonary hypertension heart lung transplant or lung transplant with repair of the heart is a possible option.

Severe pulmonary hypertension and shunt reversal are both contraindication to surgery. Our patient Mr. Abdul Khaleque is an elderly patient and already developed pulmonary hypertension. So, he is not a suitable candidate for surgical correction and we treat him medically.

\section{Conclusion:}

ES, the most advanced form of pulmonary arterial hypertension associated with congenital heart disease is a devastating condition that has a considerable impact on patient's life. Early diagnosis and operative treatment has a good prognostic value but late diagnosis with development of pulmonary hypertension and heart failure bear a bad prognosis. Most of the patients die subsequently due to heart failure, cardiac arrhythmia and thromboembolic cerebrovascular disease. Continued research to quantify the value of earlier intervention, combined regimens of targeted therapies and the potential to reverse pulmonary vascular remodeling in pulmonary artery hypertension in congenital heart disease is warranted.

\section{References :}

1. Eisenmenger V. Die angeborenen Defecte der Kammerscheidewand des Herzens. Z Klin Med .1897; 32:1-28.

2. Wood P. The Eisenmenger syndrome or pulmonary hypertension with reversed central shunt. Br Med J. 1958; 2:701-9.

3. Daliento L, Somerville J, Presbitero P. Eisenmenger syndrome. Factors relating to deterioration and death. Eur Heart J. 1998; 19:1845-55.

4. Humbert M, Morrell NW, Archer SL. Cellular and molecular pathobiology of pulmonary arterial hypertension. J Am Coll Cardiol. 2004; 43(Supp1):13S-24S.

5. Diller GP, Gatzoulis MA. Pulmonary vascular disease in adults with congenital heart disease. Circulation. 2007; 115:1039-50.

6. Kidd L, Driscoll DJ, Gersony WM. Second natural history study of congenital heart defects. Results of treatment of patients with ventricular septal defects. Circulation. 1993; 87(Suppl):138-51.

7. Humbert M, Sitbon O, Simonneau G. Treatment of pulmonary arterial hypertension. N Engl J Med. 2004; 351:1425-36. 